\title{
Reasons for Using Social Networks Professionally
}

\section{The Influence of User Diversity on Usage Motivation}

\author{
Anne Kathrin Schaar ${ }^{1}$, André Calero Valdez ${ }^{1}$, Martina Ziefle ${ }^{1}$, \\ Denise Eraßme ${ }^{2}$, Ann-Kathrin Löcker ${ }^{2}$, and Eva-Maria Jakobs ${ }^{2}$ \\ 1 Human-Computer Interaction Center and Chair for Communcation Science, \\ RWTH Aachen University, Campus Boulevard 57, 52074 Aachen, Germany \\ schaar@comm.rwth-aachen.de \\ ${ }^{2}$ Human-Computer Interaction Center and Chair for Textlinguistics and Technical \\ Communication, RWTH Aachen University, Campus Boulevard 57, 52074 Aachen, \\ Germany
}

\begin{abstract}
Since the success of social media in private usage settings, social media applications spread rapidly in the working context. In business internal contexts these applications seem useful as a measure for strategic knowledge management. Social media in this context promises to offer adequate facilities to support a systematic storage of knowledge as well as a support of knowledge exchange and communication in enterprises. But since social media is only successful when used, the usage motivation of employees is one central key for their success. Therefore this paper focusses on the motivation to use social media professionally. To achieve this we are investigating the influence of user diversity factors such as age, gender, and social media expertise on aspects of usage motivation. In a study with $\mathrm{N}=84$ the employees of an enterprise were asked which reasons for using social media are relevant to them. Findings show that both factors age and gender reveal a relatively low influence on the factors evaluation of usage motives, tools (as a measure for motivation), and incentives/reinforcements for social network usage. In contrast both expertise with social media and achievement motivation revealed many correlations with both usage motives and tools as well as incentives and reinforcements.
\end{abstract}

Keywords: social media, technology acceptance, motivation, user-centered design, incentivation.

\section{Introduction}

The integration of online social network approaches or comparable social media applications in corporate settings has started. This was triggered by the enormous success of these applications within the private utilization context [1]. According to the designation of these new forms of media as Web 2.0[2] or Social Software 3 corporate activities in the field of social media were labeled as Enterprise 2.0 [4] or Social Business [5]. Where first forms of social media integration

G. Meiselwitz (Ed.): SCSM 2014, LNCS 8531, pp. 385-396, 2014.

(C) Springer International Publishing Switzerland 2014 
were predominantly focused on business external marketing purposes, internal approaches of social media integration were more and more realized during the last 8 years e.g. the integration of social networks, wikis [6], or blogs [7, 8]. Perceived goals of internal social media integration in a corporate setting are mostly named in the context of knowledge transfer and collaboration [9] thus in line with the goals of knowledge management 10,11 .

The approaches to use social media as a new measure to support knowledge management even becomes more relevant when looking at current societal changes in big economies: Almost all big economies have to face the challenge of the so-called demographic change. A large part of the workforce of an aging population is retiring, with a shrinking workforce supplying for the elderly part of the population [12]. This does not only increase the burden on the younger part of the population to maintain a high tax volume to pay for pensions, but the upcoming generations will also have to acquire business critical knowledge from the baby boomer generation before they retire. This phenomenon is especially threatening for economies that are based on service providers. As knowledge is the central good for them [13]. Without the knowledge of experts, existing systems cannot be maintained and will deteriorate. Furthermore knowledge is required in the process of innovation [14]. Granovetter 15] proposed that the weak-ties in a social network (e.g. employee network) are the sources of information, innovation and, opportunity. Making them available is a central need of any knowledge intensive enterprise today.

From this perspective social media applications seem to be even more interesting as a support for weak-tie networks in enterprises or a room for systematic storage of knowledge as a sensitive and important good. But although business executives are highly interested in success factors or deployment strategies, so far there is only little valid knowledge about these aspects. One approach that aims to make a contribution to these questions is the user-centered community design approach that is based on knowledge from technology acceptance research.

The Approach of User-Centered Community Design. The approach of user-centered community design was developed in the research project $i N e c$. An interdisciplinary team of researchers from social sciences, computer science, economists and partners from industry investigates how to develop a social community concept that fits the needs of all involved stakeholders successfully. One central aspect of the overall approach is the user-centered perspective. This facet is based on the assumption that technology acceptance benefits from an early integration of potential users. Understanding which factors are relevant for potential users in the context of using technology, is essential for a successful technology implementation within any setting [16 19]. In the context of this paper especially the motives behind a professional use of technology are of interest. In contrast to the private usage of technology, professional usage may reveal other conditions. For example using technology for work relevant purposes may not always be voluntarily but obligatory. 
The research field of technology acceptance originated from research in social psychology, when researchers tried to understand which factors are influencing voting behavior and social behavior. Early research in this context was predominately focussed on predicting social behavior in general (Theory of Reasoned Action [20], and Theory of Planned Behavior [21]). Newer models and theories in the context of technology acceptance research focussed on the intention to use information systems within the working context. For example the Technology Acceptance Model (TAM) aims to explain behavioral intention to use an information system predicted by two factors - compatibility and relative advantage (i.e. perceived ease of use and perceived usefulness). In tradition of the TAM Venkatesh et al. [16] reformed the model into the Unified Theory of Acceptance and Use of Technology (UTAUT). The UTAUT predicts behavior using four perceptions about a system - the expected performance (i.e. perceived usefulness), expected effort (i.e. perceived ease of use), social influence (i.e. perception of a system in the peer group), and facilitating conditions (i.e. availability of support). These factors are moderated in regard to their importance by gender, age, experience and voluntariness of use.

In this context the question remains how these models can be applied to social media applications. The approach of user-centered community design tries to apply the insights from technology acceptance research with focussing on two central key aspects: a) The comprehension of employees cognitive skills, their emotional-, motivational-, and knowledge-related needs in their working environment. b) The understanding of communicative usability in the context of social media. The approach is focussed on the influence of diversity factors age, gender, social media expertise, personality, technical expertise and educational level on motivation [17], matching of incentives, and usability and design criteria.

In this paper only selected aspects of this model are investigated: age and gender, and social media expertise and achievement motivation.

Motivation to Use Social Media in Corporate Settings. In addition to general information about social media usage in corporate settings (see Section 1.1) and the presentation of the approach of user-centered community design this section deals with motivation to use social media.

It is essential to learn more about the motives behind social media usage in corporate settings, because human activity is always triggered by underlying motivation. In this context Holtzblatt et al. investigated perceived benefits and utility of wikis in 2010[11]. Three central categories that influenced people to use or not use wikis within a corporate setting were be revealed: a) the reluctance to share, which addresses the tension between necessity to share expertise across individuals and individual aspects that hinder this exchange, b) reliance on the channels of communication and c) sensitivities [11].

The first category reluctance to share consists of five factors: The extra costs of sharing information is the first aspects that influences knowledge exchange. People mentioned that strategic information sharing takes too much time and effort, because more editorial effort is necessary. The second aspect that influences the willingness to disclose information was sensitivity of information. In 
this context especially the specific culture (e.g. strictly separated business units) in an enterprises hindered exchange. The unwillingness to share unfinished work was another aspect that results from a feeling of indisposition when presenting unfinished work. A similar correlating aspect for this aspect introduced by Holtzblatt et al. was sensitivities to the openness of information, which especially focusses on hierarchy. People reported to feel uncomfortable when superiors are looking on a status quo reports. This aspect was confirmed by a study at IBM, where Danis and Singer also could reveal that people were not willing to disclose unfinished work in a wiki 22].

Reluctance to share as a more affective aspect is contrasted with reliance, which focusses on workflow aspects. Here one factor was work practice. This describes that people are not willing to learn new tools, because time is scarce or the wiki does not match their work practice. Lack of guidelines and standards irritated people when deciding which information to disclose and which not to. The third factor introduced by Holtzblatt et al. was sensitivities. It refers to cultural sensitivities according to cooperation. Holtzblatt et al. revealed the general habit that data is owned by the person who had generated it. Based on this assumption people reported that they do not want others to edit their documents or were afraid of editing other contributions.

In general we ca say that individual or cultural influences are relevant for using wikis (or other social media applications) and the way they are used. Hence it is necessary to learn more about the motives and motivation behind the scenes. The next section presents the main focus and central questions addressed in this paper.

\section{Main Focus of the Study and Questions Addressed}

In order to find out which factors impact social media usage in professional settings, we conducted this research focusing on the influence of user diversity factors on motives to use social media professionally. According to the usercentered community design approach (see Section 1.2), we focus on the influence of age, gender, and social media expertise, as well as an slightly amended short version of the Achievement Motivation Inventory (AMI) [23]. In this context the following research questions are relevant:

- Does age,gender, and level of achievement motivation influence the motives to use social media professionally?

- Does age,gender, and level of achievement motivation influence the evaluation of motivational effects of social media tools?

- Does age,gender, and level of achievement motivation influence the evaluation of incentives and reinforcements?

Overall, the impact of user diversity factors is investigated in regard of their influence on three dependent variables: general motives to use social media, tools as a motivator to use social media, and incentives and reinforcements, which might support motivation to use social media in professional usage settings. 


\section{Method}

In order to reach a large number of participants, the questionnaire method was chosen. The questionnaire was provided paper based in one manufacturing company. The questionnaire was distributed during lunch breaks, on two consecutive days and collected after lunch. Before distribution, differently aged adults examined the questionnaire to avoid misunderstandings and possible lack of clarity. Completing the questionnaire took between 25 and 30 minutes. In the following subsections the design of the study is presented: Section 3.1 contains the central variables of the study and Section 3.2 presents a description of the questionnaire instrument.

\subsection{Variables}

As independent variables we have chosen age, gender, number of contacts in most used social network, social media usage frequency, and a slightly modified short version of the Achievement Motivation Inventory (AMI).

As dependent variables we have chosen motives to use social networks professionally (see Section 3.2). In this context the participants were asked to evaluate six motives for social media usage (see Table 1). Additionally participants were asked to evaluate different social media tools according to the level they could enhance motivation social media usage. Furthermore a set of possible incentives and reinforcements for social media usage were chosen as independent variables.

\subsection{Questionnaire Instrument}

The questionnaire was divided into six main parts: (a) demographic data (b) social media experience (c) AMI (d) usage motives (e) tools and (f) possible incentives and reinforcements for social media usage. More information about the topics and the scales used are given in the subsections below:

Demographic data. In order to get general information about user diversity factors each participant was asked to state their age and gender.

Social Media Experience. This part of the questionnaire aimed to find out how experienced the participants are in using social media. Therefore the frequency of using exemplary social media applications (i.e. Facebook, Xing, Twitter, LinkedIn, Blogs, forums, Wikis, in-house network) were asked. Answers had to be selected from of a 6-point-Likert scale (daily, 2-3x/week, once a week, once a month, 2-3x/year, rarer). Asking for the degree of liking social media the participants could choose answering options from $1=$ very unwillingly to $6=$ very willingly and $7=\mathrm{I}$ dont use this product. As an additional information in this context the participants were asked for the number of contacts in the Social Network the participant uses the most. 
Usage Motives. To find out more about the motives behind social media usage in professional settings the participants were asked under which conditions they would use an internal social network ("I would use an in-house network, if ..."). Possible motives for social media use were measured by a 6 -point Likert scale ( $1=$ totally disagree $-6=$ totally agree) with 3 items for 6 different motives. All items used are presented in Table 1. All scales showed high reliability with alpha ranging from .72 to .88 and were summarized to factors for the analysis.

Table 1. List of motives for social network use in the working context

I would use a social network in the working context, when ...

\begin{tabular}{|c|c|}
\hline Motive & Items \\
\hline Information & $\begin{array}{l}\text {.. I get information about activities in my business unit } \\
\ldots \text { I could get information easier } \\
\ldots \text { I I could get information relevant for me }\end{array}$ \\
\hline Importance & $\begin{array}{l}\ldots \text { my work within the network is valued } \\
\ldots \text { my contributions matter for progress at work } \\
\ldots \text { my contributions are useful for other members }\end{array}$ \\
\hline Contact & $\begin{array}{l}\text {.. my colleagues are immediately available for me } \\
\text {.. I can stay in contact with my colleagues via the network } \\
\ldots \text {. I can socialize with my colleagues }\end{array}$ \\
\hline Self-potrayal & $\begin{array}{l}\text {.. it increases my visibility of what my skills and competences are } \\
\ldots \text {. I can present new ideas } \\
\ldots \text {. I can present my achievements }\end{array}$ \\
\hline Autonomy & $\begin{array}{l}\text {. I can work independently within the network } \\
\ldots \text { I can work at any time and at any location } \\
\ldots \text { I can plan my work more independently }\end{array}$ \\
\hline Feedback & $\begin{array}{l}\ldots \text { I get feedback from my colleagues } \\
\ldots \text { I get feedback for my work } \\
\ldots \text { I get responses according to my work }\end{array}$ \\
\hline
\end{tabular}

Tools. This part aimed to explore tools, which are likely to increase the use of inhouse Social Networks (e.g. groups, chat function, personalized profile, etc.). For this purpose the participants were asked to rate on a 6 -point Liker Scale if their motivation to use such a network would $1=$ strongly decrease to $6=$ strongly increase depending on integrated tools. In sum 27 different tools were rated.

Incentives and Reinforcements. The questionnaire presented a list of possible incentives and reinforcements that could be relevant for for the motivation to use a social network within a professional context. A list of 21 items was presented including among others financial incentives as well as gamification elements but also options on how to get feedback (e.g. only private feedback). All incentives and reinforcements had to be evaluated on a 6-point Likert scale (1 $=$ totally disagree $-6=$ totally agree). 


\section{Results}

The following section presents first the description of the sample (see Section 4.1). And second the empirical results of the study (Section 4.2 and 4.3) are presented. Results are presented according to the independent variables of the study (gender, age, social media experience, achievement motivation). As statistical methods, Mann-Whitney U, and bivariate correlation analysis were used. The level of significance was set to $\alpha=.05$. Effect sizes, if applicable, are reported using Pearson's $r$.

\subsection{Sample}

A total of $N=84$ took part in the study. Our sample consisted of 53 male and 31 female employees. Participants were recruited to voluntary complete the questionnaire in paper form during lunch break. The age ranges from 16 to 58 years $(M=36.06, S D=12.32)$. We found a wide dispersion concerning the job tenure. Some of the younger participants just started apprenticeship (some months of occupation), while the eldest employee has been working for 43 years in the company. The general job tenure was $M=14.8$ years $(S D=12.66)$ and $\mathrm{M}=9.87$ years $(S D=10.74)$. Referring to the social media expertise we can report that the sample uses especially Facebook $(M=3.25, S D=2.51)$ and the in-house community $(M=4.07, S D=2.19)$.

\subsection{The Influence of User Diverstiy on Motives to Use Social Media Professionally}

First of all the overall evaluation of otives to use social media professionally is presented (see Fig. 1). As Fig. 1 presents information, autonomy, and importance are the top motives behind social media usage. These four reached means above 4. So did also contact and feedback that were both additionally evaluated above neutral $(=3.5)$.

Gender. In the context of motives we could not reveal any influence of gender. In the context of tools that might enhance the motivation to use social media applications professionally, we could reveal a correlation between gender and the evaluation of an email distribution list as a motivator for social media usage $(U=$ $519.000, Z=-2.045, p=.041)$. In the context of incentive and reinforcements evaluation we could reveal significant gender differences for public feedback within the community $(U=547.000, Z=-2.562, p=.010)$, the option to form virtual teams that compete with each other $(U=554.500, Z=-2.223, p=.026)$ and an individual performance evaluation $(U=537.000, Z=-2.309, p=.021)$.

We can say that women reported to be more motivated by functions that support communication than male participants $\left(M_{q}=4.4, M_{\sigma^{7}}=4.0\right)$. Additionally females stated that an individual performance evaluation is more important for them $\left(M_{\uparrow}=3.3, M_{\sigma^{\prime}}=3.9\right)$. Males in contrast reported to prefer incentives and reinforcements that allow public feedback $\left(M_{\odot}=2.2, M_{\sigma^{7}}=2.9\right)$ as well as competitive reinforcements like virtual teams $\left(M_{\rho_{+}^{+}}^{+}=2.3, M_{\sigma^{7}}=3.0\right)$. 


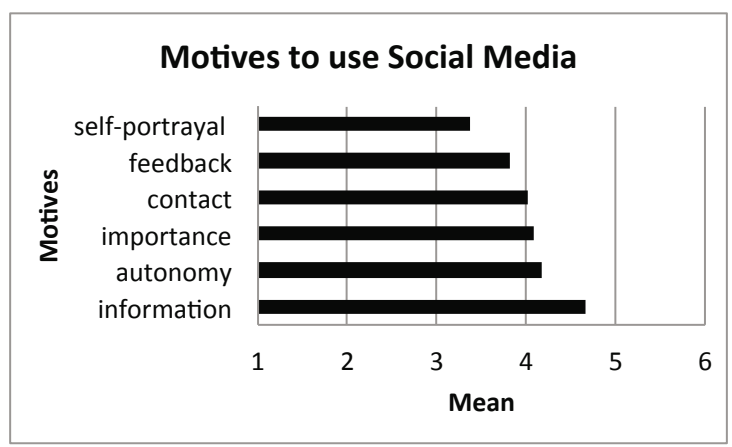

Fig. 1. Comparison of mean evaluation of motives to use social media for profssional reasons

Age. According to age we could reveal a significant correlation with the motive importance (see Table 2). For social media tools we could reveal five functions with significant correlations: There is a negative correlation between age and groups, birthday lists, messaging, and chat. For the effectiveness of incentives in the context of age we could reveal a correlation with financial incentives, which means the older a person the less open for financial incentives.

In conclusion we hold, that the older a person the more motivating the feeling of being important in the context of professional social media usage. Furthermore we can state that the older a person the less functions that could enhance communication (e.g. messaging and chat), are perceived to be motivating professional social media usage. According to incentives and reinforcements we can say that financial incentives are becoming less important with increasing age.

Social Media Experience. Correlation analysis between usage motives and social usage frequency revealed significant influences on the motives information, autonomy, contact as well as importance (see Table 2). The more often a person uses social media, the higher their agreement with the notion these motives are relevant in the context of using social media at work. Additionally we could reveal a negative correlation between the number of contacts a person has in social networks and the motive importance. Correlation analysis between social media tools and social media usage frequency revealed correlations with three functions (see Table 2). In addition to that we could reveal five correlations between number of contacts within social networks and functions. In the context of incentives and reinforcements we could not reveal any correlations with social media expertise.

Concluding we can say that the level of expertise with social media influences most motives (we investigated) to use social media. Furthermore we can say that with a higher level of social media expertise comes a more positive evaluation of tools that address personal portrayal facilities (personal profile page and upload of $\mathrm{CV}$ and business cards) as well as social media specific forms of communication 
Table 2. Bivariate correlations of Age, Social Media Expertise (SME), Number of Contacts (NOC), Achievement Motivation (AMI) and dependent variables.

\begin{tabular}{|c|c|c|c|c|}
\hline Dependent variable & Age & SME & NOC & AMI \\
\hline \multicolumn{5}{|l|}{$\overline{\text { Motives }}$} \\
\hline Importance & $.238^{*}$ & $.265^{*}$ & $-.271^{*}$ & \\
\hline Information & & $.378^{* *}$ & & \\
\hline Autonomy & & $.283^{*}$ & & \\
\hline Contact & & $.220^{*}$ & & \\
\hline Self-Portrayal & & & & $.294^{* *}$ \\
\hline \multicolumn{5}{|l|}{ Tools } \\
\hline Forming groups & $-.255^{*}$ & $.300 * *$ & & $.300^{* *}$ \\
\hline Birthday lists & $-.248^{*}$ & & $.353^{* *}$ & \\
\hline Messaging & $-.289 *$ & & $.364^{* *}$ & $.492^{* *}$ \\
\hline Chat & $-.236^{*}$ & & $.259^{* *}$ & \\
\hline Personal Profile Page & & $.231^{*}$ & $.284^{* *}$ & $.317^{* *}$ \\
\hline Upload of CV and Business cards & & $.231^{*}$ & $.297^{* *}$ & $.223^{*}$ \\
\hline Make Contacts & & & $.302^{* *}$ & $.238^{*}$ \\
\hline Privacy Settings & & & & $.273^{*}$ \\
\hline Mailing Lists & & & & $.293^{* *}$ \\
\hline Comments & & & & $.416^{* *}$ \\
\hline Posting Articles & & & & $.238^{*}$ \\
\hline Document Upload & & & & $.290 * *$ \\
\hline Calendar & & & & $.290^{* *}$ \\
\hline Surveys & & & & $.232^{*}$ \\
\hline Search & & & & $.354^{* *}$ \\
\hline \multicolumn{5}{|l|}{ Incentives and Reinforcements } \\
\hline Financial Incentives & $-.276^{*}$ & & & $.255^{*}$ \\
\hline Only Positive Feedback & & & & $.230^{*}$ \\
\hline Virtual Team Competitions & & & & $.272^{* *}$ \\
\hline Virtual Badges and Medals & & & & $.230^{*}$ \\
\hline Unlock additional functions & & & & $.335^{* *}$ \\
\hline Compensatory Time Off & & & & $.226^{*}$ \\
\hline Constructive Comments & & & & $.248^{*}$ \\
\hline Thank-You function & & & & $.348^{* *}$ \\
\hline Exchange Points for Awards & & & & $.248^{*}$ \\
\hline Virtual Favors & & & & $.318^{* *}$ \\
\hline
\end{tabular}

Levels of significance $^{*} p<.05,{ }^{* *} p<.01$ 
(e.g. chat, personal messaging). Additionally functions that facilitate the social aspect of social media like e.g. groups or birthday lists also revealed correlations with social media expertise.

Achievment Motivation (AMI). The correlation analysis of achievement motivation and usage motives revealed significant correlations for the motive self-portrayal. The higher a persons level of achievement motivation the higher the evaluation of the motive self-portrayal.

Correlation analysis with achievement motivation and social media tools revealed significant correlations for thirteen social media tools (see Table 2). In general we can say that the higher the achievement motivation the higher the evaluation of social media functions. For incentives and reinforcements we could reveal ten correlations with achievement motivation.

Summarizing we can say that the higher the achievement motivation the more important the motive self-portrayal becomes. Additionally we can state that the higher the level of achievement motivation the higher the evaluation of several social media functions as motivators and incentives and reinforcements.

Interim Summary. Finishing the result section we can summarize that gender has a relatively low influence on the motivation to use social media professionally. We can say that women are less motivated by competitive elements of social media and more open to cooperative tools. For the diversity factor age we can state that the older a person the more important the need for importance in the context of social media. Additionally we could reveal, that the older a person is, the less they are open to social media functions as motivators for a usage. Especially new communication functions that could support information exchange within a social community were negatively correlated with age. According to social media expertise we can report that many correlations could be revealed. The expertise with social media showed correlations with four usage motives (information, autonomy, contact, importance). Additionally the factors of social media expertise also revealed manifold influence on the evaluation of social media functions that addresses forms of self-portrayal and social media specific forms of communication (i.e. chat, messaging, etc.). As a third aspect we investigated the correlations between ones achievement motivation and usage motives, social media tools, and incentives and reinforcements. For motives we found the higher the level of achievement motivation the higher the assessment of the motive self-portrayal. Further more we could reveal the general trend that people with a higher level of achievement motivation showed a higher affinity to social media functions and incentives and reinforcements in general. Hence we can say that expertise with social media seems to weigh much more than other diversity facets. 


\section{Discussion and Conclusion}

As social media integration into the working context promises to be a benefit for knowledge management and thus a possible answer to the challenges of knowledge intense economies in the times of demographic change, this research focussed on reasons for social network usage in professional settings. Taking for granted the principles of the current technology acceptance research we focussed on the influence of diversity facets (age, gender, social media (technology) experience short and modified version of achievement motivation) and their influence on motives and motivation to use social media professionally. As presented the empirical results indicate, that motives to use social media professionally are less influenced by the general diversity factors age and gender, which play an important role in other contexts, but by more specific characteristics like expertise with the specific technology and a persons immanent achievement motivation. Hence one key finding of this study is that the framework conditions of technology use are the most important groundwork for the usage motivation. Especially the non-voluntary character of professional technology use implies focussing on job specific diversity factors like achievement motivation. The classical diversity factors age and gender are therefore of only secondary importance. As limitations of this research we have to name the small sample of the study as well as the branche specific view. That is why future research activities should focus on other industry branches to avoid selective results. Additionally we are working on studies that focus on people that are working with social media systems at work everyday, to get more information whether the attitude and motivation might change over time.

Acknowledgments. We would like to thank the anonymous reviewers for their constructive comments on an earlier version of this manuscript. Furthermore we would like to thank our student assistants Tatjana Hamann and Juliana Brell for their support. The studies from the "iNec" project have been funded by the German Ministry of Education and Research (BMBF) and the European Social Fund (ESF) within the program "Innovationsfähigkeit im demographischen Wandel" under the reference number 01HH11045.

\section{References}

1. Stocker, A., Müller, J.: Exploring factual and perceived use and benefits of a web 2.0-based knowledge management application: The siemens case references + . In: Proceedings of the 13th International Conference on Knowledge Management and Knowledge Technologies, p. 18. ACM (2013)

2. O'Reilly, T.: What is web 2.0 (2005)

3. Coates, T.: An addendum to a definition of social software 27, 2009 (2005) (retrieved on August)

4. McAfee, A.P.: Enterprise 2.0: The dawn of emergent collaboration. Management of Technology and Innovation 47(3) (2006) 
5. Kiron, D., Palmer, D., Phillips, A.N., Kruschwitz, N.: Social business: What are companies really doing? MIT Sloan Management Review (2012)

6. Arazy, O., Gellatly, I., Jang, S., Patterson, R.: Wiki deployment in corporate settings. IEEE Technology and Society Magazine 28(2), 57-64 (2009)

7. Efimova, L., Grudin, J.: Crossing boundaries: A case study of employee blogging. In: 40th Annual Hawaii International Conference on System Sciences, HICSS 2007, p. 86. IEEE (2007)

8. Müller, J., Stocker, A.: Enterprise microblogging for advanced knowledge sharing: The references@ bt case study. J. UCS 17(4), 532-547 (2011)

9. Paroutis, S., Al Saleh, A.: Determinants of knowledge sharing using web 2.0 technologies. Journal of Knowledge Management 13(4), 52-63 (2009)

10. Richter, A., Stocker, A., Müller, S., Avram, G.: Knowledge management goals revisited - a cross-sectional analysis of social software adoption in corporate environments. In: ACIS 2011 Proceedings (January 2011)

11. Holtzblatt, L.J., Damianos, L.E., Weiss, D.: Factors impeding wiki use in the enterprise: a case study. In: CHI 2010 Extended Abstracts on Human Factors in Computing Systems, pp. 4661-4676. ACM (2010)

12. Bloom, D.E., Canning, D.: Global demographic change: Dimensions and economic significance. Working Paper 10817, National Bureau of Economic Research (October 2004)

13. Sturgeon, T.J.: Does manufacturing still matter? The organizational delinking of production from innovation (1997)

14. Maier, R.: Knowledge management systems: Information and communication technologies for knowledge management. Springer (2007)

15. Granovetter, M.S.: The strength of weak ties. American Journal of Sociology, 1360-1380 (1973)

16. Venkatesh, V., Morris, M.G., Davis, G.B., Davis, F.D.: User acceptance of information technology: Toward a unified view. MIS Quarterly 27(3), 425-478 (2003)

17. Schaar, A.K., Calero Valdez, A., Ziefle, M.: The impact of user diversity on the willingness to disclose personal information in social network services. In: Holzinger, A., Ziefle, M., Hitz, M., Debevc, M. (eds.) SouthCHI 2013. LNCS, vol. 7946, pp. 174-193. Springer, Heidelberg (2013)

18. Calero Valdez, A., Ziefle, M., Alagöz, F., Holzinger, A.: Mental models of menu structures in diabetes assistants. In: Miesenberger, K., Klaus, J., Zagler, W., Karshmer, A. (eds.) ICCHP 2010, Part II. LNCS, vol. 6180, pp. 584-591. Springer, Heidelberg (2010)

19. Arning, K., Ziefle, M.: Understanding age differences in PDA acceptance and performance. Computers in Human Behavior 23(6), 2904-2927 (2007)

20. Ajzen, I., Fishbein, M.: Attitude-behavior relations: A theoretical analysis and review of empirical research. Psychological Bulletin 84(5), 888 (1977)

21. Ajzen, I.: The theory of planned behavior. Organizational Behavior and Human Decision Processes 50(2), 179-211 (1991)

22. Danis, C., Singer, D.: A wiki instance in the enterprise: opportunities, concerns and reality. In: Proceedings of the 2008 ACM Conference on Computer Supported Cooperative Work, pp. 495-504. ACM (2008)

23. Schuler, H., Prochaska, M.: Leistungsmotivationsinventar, hogrefe (2001) 